\title{
Appraisal of circulating biochemical markers and antioxidative activity in interferon intolerant $\mathrm{HCV}$ patients
}

\begin{abstract}
Hepatitis C is small, single stranded, enveloped positive sense RNA viruses. It is member of Hapacivirus genus, family is Flaviviridea. Transmission route is intravenous drugs, blood transfusion etc. circulating biochemical marker are indicators of pathological utter in Hepatitis C virus. Decreased antioxidants and increased oxidants expose clear picture of pathology. Here this research work we will investigated the inter relationship between the HCV patients with and without interferon therapy. Interferon is a protein released animal cells in response to entrance of virus.
\end{abstract}

Keywords: biochemical markers, interferon, hepatitis C, detoxification, plasma protein production, hormone synthesis
Volume 5 Issue 3 - 2018

\author{
Muhammad Salabat Khan, Sajid Ali \\ Shaanxi Normal University, China
}

\begin{abstract}
Correspondence: Muhammad Salabat Khan, PhD student, Shaanxi Normal University, College of Life Sciences, Shaanxi Normal University, Xi'an, Shaanxi, 7I0062, China, Tel +0086I5094064283, Email salabatktan I00@gmail.com
\end{abstract}

Received: August 12, 2016 | Published: November 08, 2018

\section{Introduction}

The liver is a vital organ which is present in vertebrates and some animals. It works as a wide range of functions, including detoxification, synthesis of protein, glycogen store room, breakdown of red blood cells, detoxification, plasma protein production, hormone synthesis and manufacture of biochemical's required for digestion. Hepatitis $\mathrm{C}$ is the infectious disease which affects the liver, causative agent is hepatitis $\mathrm{C}$ virus. The infection may be in some time asymptomatic but chronic infection ultimately changed to cirrhosis, which is commonly apparent after some years. In some cases cirrhosis changed to liver cancer, liver failure, esophageal, gastric varices. ${ }^{1}$ Liver cirrhosis caused different complications which are jaundice, bleeding, as cites, portal hypertension, varices, and hepatic encephalopathy. These are the most common causes of the liver transplant. ${ }^{2}$ Hepatitis $\mathrm{C}$ is commonly associated with the diabetes mellitus, thrombocytopenia, lymphoproliferative disorders, lichen planus and sijogren syndrome (an autoimmune syndrome). It is estimated that thrombocytopenia is present in $0.16-45.4 \%$ of the people in hepatitis C virus. Hepatitis C is also linked with the cryoglobulinemia which is the inflammation of small and medium size blood vessels caused the deposition of immune complexes in which cry globulins are involved. Hepatitis $\mathrm{C}$ is the small, single-stranded, enveloped, positive sense RNA virus. Its family is Flaviviridae. Hepatitis $\mathrm{C}$ has seven major genotypes which represented as one to seven. Approximately $70 \%$ cases are caused by genotype $1,20 \%$ genotype $2,1 \%$ each of the other genotypes. Genotype 1 is most commonly found in Europe. ${ }^{3}$ Treatment consists of pegylated interferon and ribiviron for the period of 24-48 weeks, depending upon the $\mathrm{HCV}$ genotype ${ }^{4}$ Cirrhosis is the result of damaging of the liver cells from toxins, inflammation metabolic derangement and others chronic liver diseases, such as hemochromatosis, caused the inability of liver to perform its biochemical function. Its infection occur due to the long -lasting use of the alcohol, hepatitis B, hepatitis C Piekarska \& Matusiak ${ }^{5}$ hepatocellular carcinoma is a type of cancer which damage the hepatocytes that is major cell type of the liver. Throughout the world it is considered the number one or number two cause of cancer death. Chronic infection which are HBV and HCV are increased the risk of hepatocellular carcinoma. About $80 \%$ people who suffer in hepatocellular carcinoma have cirrhosis. ${ }^{6}$
Endogenous oxidants are generated by multiple intracellular pathways and are important class of naturally occurring carcinogens. During aerobic metabolism ROS and endogenous oxygen containing molecules formed as normal product during aerobic metabolism.? ROS include the number of species such as superoxide, hydroxyl, and peroxyl radicles and certain non radical such as single oxygen and hydrogen peroxide that may be easily converted into radicals. ROS caused the chromosomal alteration and genetic mutation and contribute to cancer development in multi step carcinogenesis. ${ }^{8,9} \mathrm{~A}$ study demonstrated ROS at submicromolar level act as novel intra and intercellular secondary messengers and modulates various aspects of cellular function including gene expression, apoptosis and proliferation. ${ }^{10}$ Mostly markers of oxidative injury used reflect free radicals attack on polyunsaturated fatty acids with the classical route of attack involving lipid peroxidation which generates end peroxides and hydro peroxides.

Moreover it has been showed that patient with chronic hepatitis $\mathrm{C}$ virus increased the production of the tumor necrosis factor-Alfa .Tumor necrosis factor-Alfa is a cytokine that can produced the oxidative stress by stimulating the generation of reactive oxygen species such as hydrogen peroxide $\operatorname{ion}\left(\mathrm{H}_{2} \mathrm{O}_{2}\right)$ and super oxide ion $\left(\mathrm{O}_{2}\right)$. ROS can damage cells and oxidative damage of DNA, proteins, and by depleting ATP stores. Metals such as $\mathrm{Fe}^{3+}, \mathrm{O}_{2}$ - react with $\mathrm{H}_{2} \mathrm{O}_{2}$ to generate a hydroxyl radical that changed to more reactive and cytotoxic than $\mathrm{O}_{2}$ - or $\mathrm{H}_{2} \mathrm{O}_{2}{ }^{11}$ Free radicals work as a scavenger to the several metalloenzymes such as, glutathione peroxidase, catalase, and superoxide dismutase as well as by the non-enzymatic antioxidant defense system such as vitamin $\mathrm{C}$, lipoic Acid, ubiquinol, glutathione, metallothionein, Bilirubin, $\beta$ - carotene. That is the reason, much attention of nutritionists have focused to the possible role of enhancement of the defenses against ROS. ${ }^{12}$ Reactive nitrogen species (RNS) are generated because of the production of the ROS caused the loss of the antioxidant defense. ROS/RNS are usually too reactive and have a very short half- life period may be much shorter than second therefore allow direct measurement in body fluids, tissues and cell. It is also used in measuring stable metabolites e.g. nitrate and nitrite. ${ }^{13,14}$

Malondialdehyde (MDA) is a highly reactive three carbon compound which is also called di aldehyde. It produced as a 
byproduct of polyunsaturated fatty acid peroxidation and during metabolism of arachidonic for synthesis of prostaglandin. ${ }^{14,15}$ MDA have ability to combine with several functional groups on molecules including protein, lipoprotein, RNA and DNA. MDA level are used for the important indicator of lipid peroxidation in vitro and vivo for various diseases. To check the cellular injury lipid peroxidation is a well established mechanism of cellular injury in both animals and plants and it is also used for indication the oxidative stress in tissues and cells. ${ }^{16}$ It is reported that MDA induced in various conditions such as hepatitis $\mathrm{C}$ infection, smoking, diabetes and HIV seropositive children.

Many reports indicated that glutathione plays an important role in defence against the reactive oxygen species. ${ }^{17,18}$ Cellular enzymes e.g; glutathione peroxidase and related enzymes glutathione s-transferase and glutathione reductase provides the principle mechanism against exogenous endogenous and exogenous free radicals and toxic substances damage the liver and other tissues. ${ }^{19}$ Glutathione is a naturally occurring antioxidant ant it plays important role against the oxidative stress to reduce the disulphide linkages of the protein by scavenging hydro peroxides and lipid peroxide. Glutathione found both in reduced and oxidized form under the normal condition reduced form is $99.5 \%$ and oxidized form is $0.5 \%$ which may be cytotoxic. ${ }^{20}$ Glutathione is the detoxification enzyme which catalysis the addition of the glutathione into various xenobiotic. ${ }^{21}$ Glutathione- $\alpha$ has high concentration in the liver cell hepatocytes crystal. ${ }^{22}$

According to the experimental model it has been proposed that oxidative stress may lead to neoplastic transformation. Therefore presence of primary in the course of cirrhosis of $\mathrm{HBV}, \mathrm{HCV}$ or other ethology may be associated with disturbances of organism antioxidant barrier. ${ }^{15}$

The amount of SOD and GSH-Px reduced in liver which indicates decreased the capacity of liver and the antioxidant defense power of the patient with chronic hepatitis C. Researchers proved that lipid peroxidation increased due to viral inflammation and decreased the antioxidant level may be an early marker of the oxidative stress. Lipid peroxide can be chemotactic for the neutrophils causing increased inflammation which further increased the oxidative injury in the liver. ${ }^{23}$ Peripheral lymphocytes are also infected to the viral infection in the hepatitis $\mathrm{C}$. lymphocytes which are infected to the hepatitis $\mathrm{C}$ produced the interferon to stimulate healthy cells against viruses. The mechanism through which HCV causes cell damage remain obscure, although it is claimed that oxidative stress may play pathogenic role in the infection. Hepatitis $\mathrm{C}$ patient exhibit increased production of TNF- $\alpha$, a cytokine that can produced oxidative stress by stimulating the production of oxygen ROS. ${ }^{21}$ No vaccine against hepatitis $\mathrm{C}$ is available. IFNs belong to the large class of glycoproteins known as cytokines. Interferons are named after their ability to "interfere" with viral replication within host cells. IFNs have other functions: they activate immune cells, such as natural killer cells and macrophages; they increase recognition of infection or tumor cells by up-regulating antigen presentation to $\mathrm{T}$ lymphocytes; and they increase the ability of uninfected host cells to resist new infection by virus. Certain symptoms, such as aching muscles and fever, are related to the production of IFNs during infection. About ten distinct IFNs have been identified in mammals; seven of these have been described for humans. They are typically divided among three IFN classes: Type I IFN, Type II IFN, and Type III IFN. IFNs belonging to all IFN classes are very important for fighting viral infections. Alpha interferon has been used since 1980s in the chronic hepatitis C which are given as subcutaneous injection. ${ }^{24,25}$ Interferon and addition of oral ribiviron to them has brought their rate of long term viral clearance to them from
$<5 \%$ to now approximately who have never been received and $50 \%$ in those patients who never been received treatment. ${ }^{26,27}$ However side effects of the interferon are universal. This lead to the modifications of the dosage of the interferon or ribiviron in $35-45 \%$ patients of the patient treated with pegylated interferon in a large, randomized clinical trials and discontinuation of therapy in $14-19 \%$ of the patients. ${ }^{28}$ In each trial fatigue is the major side effect of the interferon and ribiviron. It is partly a direct side effect of interferon- alpha with stimulation of immune response to release cytokines and other factors that causes fatigue. This is partly related to anemia caused by ribiviron. Ribiviron is toxic to RBC because it directly breaks down the red blood cell, giving the median decline in hemoglobin approximately $3 \mathrm{~g} / \mathrm{dl} .{ }^{27}$ Depression is also a major side effect which is $20-35 \%$ of patients treated with interferon and ribaviron. This can be one of the major morbidities related with treatment and practitioner screening for the development of suicidal and other ideas are essential when patient develops symptoms of depression. Patient prior history of depression or other mental illness by mental health professionals, with appropriate treatment before treatment is very important. Serotonin reuptake inhibitor (SSRIs) is found to be effective for the treatment of the depression associated with interferon therapy. ${ }^{29}$

Ribiviron causes dosage dependent hemolytic anemia but interferon can stop red blood cell production in bone marrow, this result anemia. Likely $>20 \%$ of patients are treated with ribiviron and pegylated interferon at $1000-1200 \mathrm{mg} /$ day. ${ }^{28}$ Anemia can be a most clinically significant side effect of the therapy and patients with condition that can be worse by anemia such as chronic obstructive pulmonary disease and coronary artery disease. Patient who is coinfected with HIV may be more susceptible to developing anemia due to treatment. ${ }^{30}$ Ribiviron dosage reduction should be the first step to manage the symptomatic anemia. The efficacy of ribiviron may be dosage related. Therefore doses should be maintained at $800 \mathrm{mg} /$ day or more if possible. Manufacturer recommended reducing ribiviron dosage (to $600 \mathrm{mg} /$ day for Capegous and $200 \mathrm{mg} /$ day for Rebetol) with hemoglobin $<10 \mathrm{~g} / \mathrm{dl}$ and discontinuing ribavirin with hemoglobin $>8.5 \mathrm{~g} / \mathrm{dl}$. Interferon affects the tongue and caused dysfunctioning of taste bud cells, killing taste bud entirely. ${ }^{31}$

\section{Materials and methods}

\section{Biochemical assays for liver function tests}

One milliliter blood sample were taken and subjected to centrifuge at 3000-4000rpm for 10-15minutes for the separation of serum. The estimation of Aspartate Amino Transferase (AST), ALT Rietman and Frankle, ALP, Ochoa, was estimated by using commercially available Bio Merux and Randox kits and following their protocol.

\section{Estimation of aspartate amino transferase (AST)}

$\alpha$ - oxoglutarate reacts with L- aspirate in the presence of AST to form $\mathrm{L}$ glutamate plus oxaloacetate. The indicator reaction utilizes the oxaloacetate for a kinetic determination of NADH consumption Anonymous

$\alpha$-oxoglutarate $+\mathrm{L}$ - aspirate AST L - glutamate + oxaloacetate

Oxaloacetate $+\mathrm{NADH}+\mathrm{H}^{+} \mathrm{MDH} \mathrm{L}-$ malate $+\mathrm{NAD}^{+}$

One milliliter reagent was taken in all the tubes by pipette and $100 \mu 1$ of each serum sample was taken in tube. Contents of tube was mixed and then incubated at $37^{\circ} \mathrm{C}$ for $5 \mathrm{~min}$. after incubation $250 \mu \mathrm{l}$ of substrate from the kit was added to all the tubes. The contents were again mixed for $1.0 \mathrm{~min}$ and then absorbance of sample was measured after 1, 2 and 3 minutes at $404 \mathrm{~nm}$ Anonymous. The concentration of 
AST was estimated by applying the following formula:

$\Delta \mathrm{A} / \min \times 1745\left(\right.$ at $37^{\circ} \mathrm{C}$ ) where $\Delta \mathrm{A}=$ Change in absorbance

While Reference values for men and women were $15-40 \mathrm{IU} / \mathrm{L}$ and 13-35IU/L respectively.

\section{Estimation of alanine aminotransferase (ALT)}

ALT converts $\alpha$-oxoglutarate and L- alanine to L- glutamate and pyruvate. This pyruvate is further converted to L- lactate and NADH is converted to $\mathrm{NAD}^{+}$Anonymous.

$$
\begin{aligned}
& \alpha \text {-oxoglutarate }+\mathrm{L} \text { - alanine ALT L - glutamate }+ \text { pyruvate } \\
& \text { Pyruvate }+\mathrm{NADH}+\mathrm{H}^{+} \mathrm{LDH} \quad \mathrm{L} \text { - lactate }+\mathrm{NAD}^{+}
\end{aligned}
$$

One milliliter reagent was taken in all the tubes by pipette and $100 \mu 1$ of each serum sample was taken in tube. Contents of tube was mixed and then incubated at $37^{\circ} \mathrm{C}$ for $5 \mathrm{~min}$. after incubation $250 \mu \mathrm{l}$ of substrate from the kit was added to all the tubes. The contents were again mixed for $1.0 \mathrm{~min}$ and then absorbance of sample was measured after 1, 2 and 3minutes at $404 \mathrm{~nm}$ Anonymous. The concentration of ALT was estimated by applying the following formula:

$\Delta \mathrm{A} / \min \mathrm{x} 1745\left(\right.$ at $37^{\circ} \mathrm{C}$ ) where $\Delta \mathrm{A}=$ Change in absorbance

While reference values for men and women were 10-40IU/L and 07-35IU/L respectively.

\section{Estimation of alkaline phosphate (ALP)}

In the presence of ALP p-nitrophenylphosphate is hydrated to p-nitrophenol and phosphate Anonymous. P-nitrophenylphosphate+ $\mathrm{H}_{2} \mathrm{O}$ ALP phosphate + p-nitrophenol

One milliliter reagent was taken in all the tubes by pipette and $100 \mu 1$ of each serum sample was taken in tube. Contents of tube was mixed and then incubated at $37^{\circ} \mathrm{C}$ for $5 \mathrm{~min}$. after incubation $250 \mu \mathrm{l}$ of substrate from the kit was added to all the tubes. The contents were again mixed for $1.0 \mathrm{~min}$ and then absorbance of sample was measured after 1, 2 and 3 minutes at $404 \mathrm{~nm}$ Anonymous. The concentration of ALP was estimated by applying the following formula:

\section{$\Delta \mathrm{A} / \min \mathrm{x} 3433\left(\right.$ at $37^{\circ} \mathrm{C}$ ) Where $\Delta \mathrm{A}=$ Change in absorbance}

Reference values for serum / plasma was taken as 64-306IU/L.

Hemoglobin: Hemoglobin concentration was determined using cyanmeth reagent.

Total Bilirubin Levels: Total Bilirubin levels of serum were measured by the method of Jendrassik \& Groff.

\section{Estimation of glutathione (GSH)}

Liver GSH was estimated according to the method of Moron et al. GSH reacts with Elman's reagent (5, 5-dithio bis (Nitro benzoic acid) or DTNB) to produce a chromophore TNB with maximal absorbance at $412 \mathrm{~nm}$ and oxidized glutathione GSSG. The amount of glutathione measured represents the sum of reduced and oxidized glutathione in the sample $([\mathrm{GSH}] \mathrm{t}=[\mathrm{GSH}]+2 \times[\mathrm{GSSG}])$. The rate of absorbance change $(\triangle \mathrm{A} 412 \mathrm{~nm} / \mathrm{min})$ is made to be linear for the convenience and consistence of measurement, and is linearly proportional to the total concentration of GSH. The concentration of an unknown (sample) is determined by calculating from the linear equation generated from several standards of glutathione Tietze.

Standard Curve Calculations

$\mathrm{Y}=0.0167 \mathrm{X}-0.0098$

$$
\begin{aligned}
& \mathrm{X}=\frac{\mathrm{Y}+0.0098}{0.0167} \\
& \mathrm{R}^{2}=0.902 \\
& \mathrm{X}=\text { Concentration of GSH } \\
& \mathrm{Y}=\text { Absorbance of Sample }
\end{aligned}
$$

\section{Estimation of catalase (CAT)}

Catalase was assayed according to the method of Aebi. The estimation was done using spectrophotometer by checking the decrease in absorbance at $230 \mathrm{~nm}$. The liver tissue was homogenized in $\mathrm{M} / 150$ phosphate buffer $(\mathrm{pH} 7.0)$ at $1-4^{\circ} \mathrm{C}$ and centrifuged at 5000rpm. The reaction mixture contained $0.01 \mathrm{M}$ phosphate buffer $(\mathrm{pH} 7.0) 2 \mathrm{mM}$ $\mathrm{H}_{2} \mathrm{O}_{2}$ and the enzyme extract. The specific activity of Catalase was expressed in terms of units/gram of liver tissue. Absorbance values were compared with a standard curve generated from known Catalase.

$$
\begin{aligned}
& \text { Standard Curve Calculations } \\
& Y=-0.0065 \mathrm{x}+1.1595 \\
& \mathrm{X}=\frac{1.1595-\mathrm{Y}}{0.0065} \\
& \mathrm{R}^{2}=0.9934 \\
& \mathrm{X}=\text { Concentration of CAT } \\
& \mathrm{Y}=\text { Absorbance of sample }
\end{aligned}
$$

\section{Estimation of thiobarbituric acid reactive substances (TBARS)}

Lipid peroxidation in liver tissues was estimated calorimetrically by measuring Thiobarbituric acid reactive substances (TBARS) by the method of Ohkawa. To $0.2 \mathrm{ml}$ of sample, $0.2 \mathrm{ml}$ of $8.1 \%$ Sodium dodecyl sulfate (SDS), $1.5 \mathrm{ml}$ of $20 \%$ acetic acid and $1.5 \mathrm{ml}$ of $0.8 \%$ TBA were added. After centrifugation at $3000 \mathrm{rpm}$ for $10 \mathrm{~min}$ the upper organic layer was taken and its OD was read at $532 \mathrm{~nm}$ against an appropriate blank without the sample. The levels of lipid peroxides were expressed as milimoles of Thiobarbituric acid reactive substances (TBARS)/g of liver tissue using standard curve.

$$
\begin{aligned}
& \text { Standard Curve Calculations } \\
& \mathrm{Y}=-0.129 \mathrm{X}+0.592 \\
& \mathrm{X}=\frac{0.129-\mathrm{Y}}{0.592} \\
& \mathrm{R}^{2}=0.8952 \\
& \mathrm{X}=\text { Concentration } \\
& \mathrm{Y}=\text { Absorbance of sample }
\end{aligned}
$$

\section{Estimation of Super Oxide Dismutase (SOD)}

Superoxide dismutase (SOD) activity was determined by the method of Kakkar. The assay mixture contained $0.1 \mathrm{ml}$ of sample, $1.2 \mathrm{ml}$ of sodium pyrophosphate buffer $(\mathrm{pH} 8.3,0.052 \mathrm{M}), 0.1 \mathrm{ml}$ of Phenazine methosulphate $(186 \mu \mathrm{m}), 0.3 \mathrm{ml}$ of nitro blue tetrazolium $(300 \mu \mathrm{m}), 0.2 \mathrm{ml}$ of NADH $(750$ mile). Reaction was started by addition of NADH. After incubation at $300 \mathrm{C}$ for $90 \mathrm{sec}$, the reaction was stopped by the addition of $0.1 \mathrm{ml}$ of glacial acetic acid. The reaction mixture was stirred vigorously with $4.0 \mathrm{ml}$ of n-butanol. The mixture was allowed to stand for 10 min; centrifuged and n-butanol layer was separated. The color intensity of the chromogen in butanol 
layer was measured at $560 \mathrm{~nm}$ against n-butanol and concentration of SOD was expressed as units/g of liver tissue. Absorbance values were compared with a standard curve generated from known SOD.

$$
\begin{aligned}
& \text { Standard Curve Calculations } \\
& \mathrm{Y}=0.0162 \mathrm{x}+0.0161 \\
& \mathrm{X}=\frac{0.0162-\mathrm{Y}}{0.0161} \\
& \mathrm{R}^{2}=0.889 \\
& \mathrm{Y}=\text { Absorbance of the sample } \\
& \mathrm{X}=\text { Concentration of SOD }
\end{aligned}
$$

\section{Estimation of zinc}

Zinc present in the sample is chelated by 5-Br-PAPS 2-(5-bromo2-pyridylazo)-5-(N-propyl-N-sulfopropylamino)-phenol in the reagent. The formation of this complex is measured at the wavelength of $560 \mathrm{~nm}$. Before use all glassware were immersed in dilute $\mathrm{HCl}$ or dilute $\mathrm{HNO}_{3}$ and then rinsed in $\mathrm{DDH}_{2} 0$. Special care was taken as rubber cap of commercial control serum or sample tube can be a cause of zinc contamination. Sample was properly mixed by vortex after the addition of deproteinizing reagent to sample. Reference value was taken as $10-17 \mu \mathrm{mol} / \mathrm{L}$.

$$
\frac{\mathrm{A}_{\text {sample }}-\mathrm{A}_{\text {blank }}}{\mathrm{A}_{\mathrm{S} \text { tan dard }}-\mathrm{A}_{\text {blank }}} \mathrm{X} \text { Standard Conc }
$$

\section{Statistical analysis}

Results have been expressed as Mean \pm SD (Standard Deviation). Statistical significance was determined by one way analysis of variance and Pearson correlation (Two Tailed) was used to correlate the different variables. The difference were considered significant at $\mathrm{p}<0.05$.

\section{Results}

Hematological Profiles of Hepatitis C Patients Receiving Interferon Vs Interferon Intolerant HCV Subjects The results regarding hemoglobin and RBC profile in Figure 1 demonstrating statistically highly significant differences and consistent decreasing (hemoglobin) and increasing Vitamin E (Figure 1) in the interferon intolerant $\mathrm{HCV}$ subjects $(\mathrm{P}=0.04)$. The lowest value $(10.42 \%)$ of hemoglobin was recorded in interferon subjected patients in group $\mathrm{C}$ and highest $(15.37 \%)$ in group A (served as control). Vitamin E is a highly effective fat-soluble vitamin with a variety of cellular membrane stabilizing-antioxidant and non-antioxidant functions. Vitamin E has been suggested to prevent the oxidation of polyunsaturated fatty acids in red blood cell (RBC) membrane, thus inhibiting the premature erythrocyte lysis. Animal studies have shown that treatment with vitamin $\mathrm{E}$ results in increased number of colony forming units of elytroid precursors, enhanced erythropoiesis and improved blood hemoglobin levels in these animals. ${ }^{32}$

Vitamins Profiles of Hepatitis C Patients Receiving Interferon Vs Interferon Intolerant HCV Subjects Vitamin A shows the highly significant difference $(\mathrm{p}=0.001)$ between the Vitamin $B 1$. Lowest value of vitamin $\mathrm{A}$ is $(0.63 \%)$ in interferon receiving patients and highest value is $(1.02 \%)$ which is present in control served. HBV or $\mathrm{HCV}$ infection enhanced oxidative stress and lowered vitamin $\mathrm{B}$ in circulation. In order to avoid other healthy risk, nutrition status should be monitored and limitations or supplementation of certain nutrients might be helpful HBV or HCV infected patients.

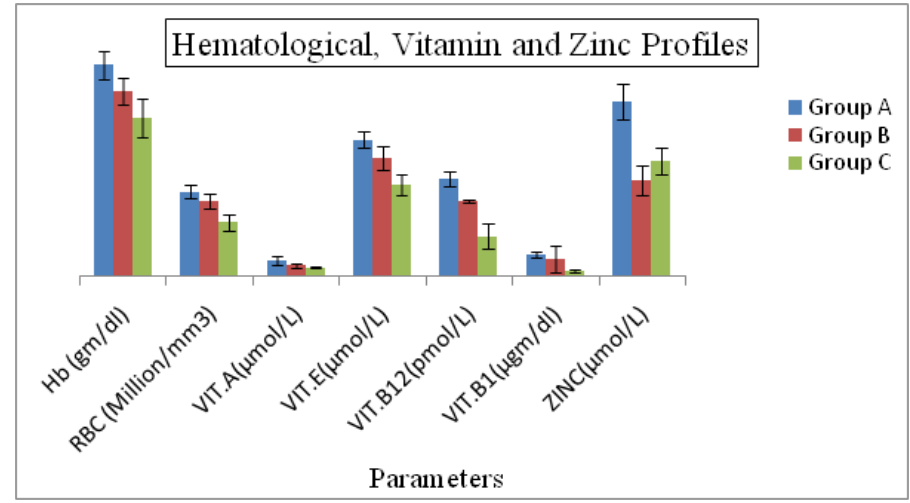

Figure I Hematological, Vitamin and Zinc Profiles of Hepatitis C Patients Receiving Interferon Vs Interferon Intolerant HCV Subjects.

Group A= Served as control Group B= Represents interferon intolerant HCV subjects and Group $\mathrm{C}=\mathrm{HCV}$ subjects receiving interferon therapy. Values of Vitamin B 12 of all three groups were divided by 100 to fit well in graphical area. Values represented are means of three independent repeats and were checked at significance level $<0.05$.

Zinc Profiles of Hepatitis C Patients Receiving Interferon Vs Interferon Intolerant HCV Subjects Zinc is very significant biomarkers in our study because zinc shows the low level in interferon intolerance patients as compared to the interferon subjected positive patients. That can be reason for their intolerance in interferon intolerance patients. Their fore according to my finding the patients who are interferon intolerance, if give the zinc with interferon therapy can lead to the interferon positive therapy. Some research also proved that interferon intolerance patients show the low level of zinc in patients.

Hepatic Profiles of Hepatitis C Patients Receiving Interferon Vs Interferon Intolerant HCV Subjects From the results presented in Figure 2 shows that all the tested circulating biochemical markers e.g. aspartate aminotransferase (AST) shows the highly significant differences $(\mathrm{p}=0.04, \mathrm{p}=.000, \mathrm{p}=0.02)$ between the (LDL, Vit. A,Vit. B1). The lowest value $(21.33 \%)$ of aspartate aminotransferase was recorded in normal patients in group A and highest value (61.43\%) was observed in interferon subjected patients in group C. Alkaline phosphates (ALP) and exhibited highly significant ( $\mathrm{P}=0.03$ respectively) differences between Vitamin E. The lowest value of aspartate aminotransferase $(204.88 \%)$ was recorded in normal patients in group A and highest value (387.34\%) was observed in interferon subjected patients in group C. An association of hepatitis $\mathrm{C}$ virus (HCV) with low-density lipoproteins (LDL) in serum of patients with chronic hepatitis $\mathrm{C}(\mathrm{CHC})$ has been suggested. We conducted a prospective study in $\mathrm{CHC}$ patients complicated with hyperlipidemia, to examine whether bezafibrate, which is commonly used for treatment of hyperlipidemia, reduces serum HCV-RNA titer and improves liver dysfunction. Fifteen patients received daily oral bezafibrate treatment $(400 \mathrm{mg} /$ day) for 8 weeks, and its effects on serum lipids, transaminases, HCV-RNA titers, and HCV-RNA titers bound to LDL were evaluated. Fifteen untreated patients with $\mathrm{CHC}$ and hyperlipidemia were used as controls. The mean serum alanine aminotransferase levels and HCV-RNA titers significantly decreased at the end of bezafibrate therapy in the treated group (105 \pm 34 to $80 \pm 32 \mathrm{IU} / \mathrm{L}, \mathrm{P}=0.02$ and $2.23 \pm 2.71$ to $1.78 \pm 2.38 \times 107$ copies $/ \mathrm{mL}$, $\mathrm{P}<0.01$ respectively), but no changes were observed in the control group. Serum HCV-RNA titers bound to LDL, as quantified by immunoprecipitation using anti-LDL antibody, also decreased in all 15 treated patients $(5.55 \pm 6.59$ to $1.07 \pm 1.58 \times 106$ copies $/ \mathrm{ml}, \mathrm{P}<0.01$ (mean reduction rate was $-78.5 \pm 17.0 \%$ ). 


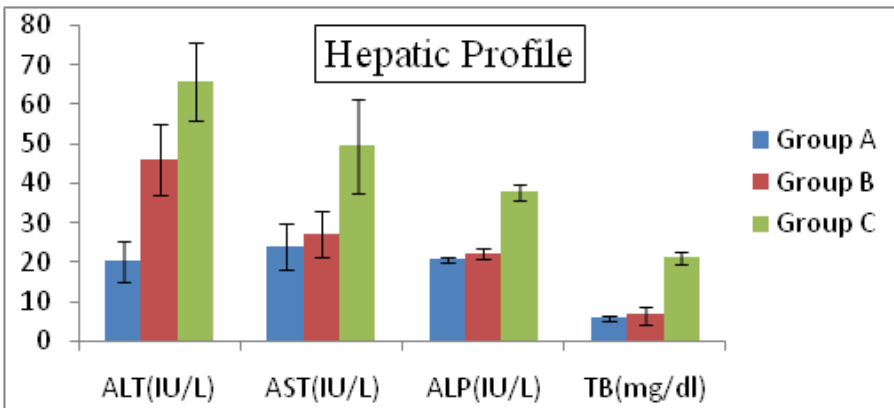

Parameters

Figure 2 Hepatic Profiles of Hepatitis C Patients Receiving Interferon Vs Interferon Intolerant HCV Subjects.

Group A = Served as control Group B= Represents interferon intolerant HCV subjects and Group $C=H C V$ subjects receiving interferon therapy. Values of ALP of all three groups were divided by 10 and values of TB were multiplied by 10 to fit well in graphical area. Values represented are means of three independent repeats and were checked at significance level $<0.05$.

Lipid Profiles of Hepatitis C Patients Receiving Interferon Vs Interferon Intolerant HCV Subjects The results depicted in Figure 3 reflecting that the lipid profile Total Cholesterol $(\mathrm{TCh})$ and Triglyceride (Tg) shows differed significantly $(\mathrm{P}=0.002$ and $\mathrm{p}=0.01$ respectively) with the glutathione (GSH) Figure 4. The lowest value (4.26\%) of Total Cholesterol was recorded in normal patients in group A and highest value $(5.89 \%)$ was observed in interferon subjected patients in group C. In the triglyceride (TG) lowest value $(1.17 \%)$ of was recorded in normal group A and highest value $(1.79 \%)$ was observed in interferon intolerance $\mathrm{HCV}$ subjects in group B. The cumulative incidence rates of $\mathrm{HCC}$ were $24 \%, 51 \%$, and $63 \%$ at 5 years, 10 years, and 15 years, respectively. Multivariate analysis identified hepatic steatosis, together with aging, cirrhosis, and no IFN treatment, as independent and significant risk factors for HCC $(\mathrm{P}=0.0135, \mathrm{P}=$ $0.0390, \mathrm{P}=0.0068$, and $\mathrm{P}=0.0142$, respectively). In addition, hepatic steatosis was correlated with BMI, serum ALT levels, and triglyceride levels. Kazuyuki Ohata.

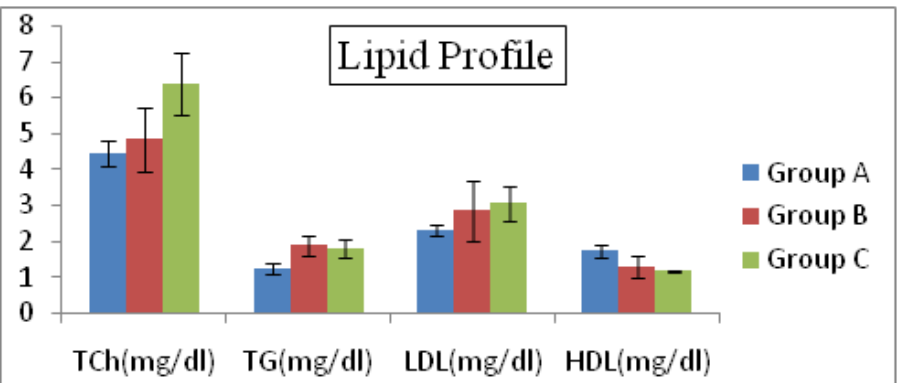

Parameters

Figure 3 Lipid Profiles of Hepatitis C Patients Receiving Interferon Vs Interferon Intolerant HCV Subjects.

Group A= Served as control Group B= Represents interferon intolerant HCV subjects and Group $\mathrm{C}=\mathrm{HCV}$ subjects receiving interferon therapy. Values represented are means of three independent repeats and were checked at significance level $<0.05$

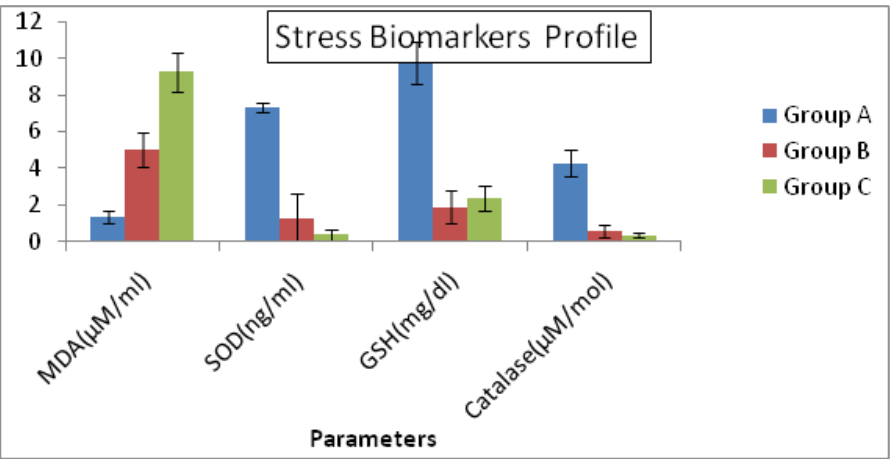

Figure 4 Stress Biomarkers Profiles of Hepatitis C Patients Receiving Interferon Vs Interferon Intolerant HCV Subjects.

Group $A=$ Served as control Group B= Represents interferon intolerant HCV subjects and Group C= HCV subjects receiving interferon therapy. Values of SOD of all three groups were multiplied by 10 to fit well in graphical area. Values represented are means of three independent repeats and were checked at significance level $<0.05$.

\section{Discussion}

The intracellular concentration of ROS is tightly regulated by multiple defense mechanisms involving ROS scavenging enzymes and small antioxidant molecules. Among these antioxidant systems acting as antioxidants or scavengers are glutathione and GSHdependent enzymes, which are one of the protective mechanism vs oxidative damage, both in the circulation and in various tissues, including liver. ${ }^{12}$ A wide variety of oxidizing molecules such as ROS and/or depleting agents can alter the glutathione redox state, which is normally maintained by the activity of GSH-depleting (GSH-Px, GST) and GSH-replenishing (GSHR) enzymes. ${ }^{32,33}$ In the present study we determined that $\mathrm{Hb}$ has significant differences to the vitamin E interferon intolerant HCV subjects. These are negatively correlated, if the hemoglobin increases then the vitamin will decrease, likewise if the vitamin $\mathrm{E}$ will increase then the hemoglobin will decrease. Vitamin $\mathrm{E}$ is a highly effective fat-soluble vitamin with a variety of cellular membrane stabilizing-antioxidant and non-antioxidant functions. When we look the hematological profile in which red blood cells and hemoglobin have lower values in interferon subjected HCV patients as compared to the interferon intolerance and control group patients? This may be due to the increased breakdown of the red blood cells and therefore decreased level of the RBC and $\mathrm{Hb}$.

Vitamin E has been suggested to prevent the oxidation of polyunsaturated fatty acids in red blood cell (RBC) membrane, thus inhibiting the premature erythrocytelysis. Animal studies have shown that treatment with vitamin $\mathrm{E}$ results in increased number of colony forming units of elytroid precursors, enhanced erythropoiesis and improved blood hemoglobin levels in these animals. ${ }^{33}$

AST is negatively correlated with the LDL, if AST level increases then LDL level decreases. Alkaline phosphates (ALP) exhibits highly significant $(\mathrm{P}=.03$ respectively) differences between Vitamin $\mathrm{E}$. The lowest value of aspartate aminotransferase (204.88\%) was recorded in normal patients in group A and highest value (387.34\%) was observed in interferon subjected patients in group $\mathrm{C}$. The hepatic profile showed the highest values of AST, ALT, ALP and total bilirubin in the interferon subjected patients as compared to the interferon intolerance patients. We give interferon to the patients for cure purpose but it also have opposite results. Some research proved that interferon is itself Hepatotoxicity therefore it will damage the hepatocytes and 
the enzyme AST present in the cell membrane and the ALT and ALP present in cytoplasm come to the blood which indicates the hepatocyte damage.

An association of hepatitis C virus (HCV) with low-density lipoproteins (LDL) in serum of patients with chronic hepatitis $\mathrm{C}$ (CHC) has been suggested. We conducted a prospective study in $\mathrm{CHC}$ patients complicated with hyperlipidemia, to examine whether bezafibrate, which is commonly used for treatment of hyperlipidemia, reduces serum HCV-RNA titer and improves liver dysfunction. Fifteen patients received daily oral bezafibrate treatment $(400 \mathrm{mg}$ / day) for 8 weeks, and its effects on serum lipids, transaminases, HCV-RNA titers, and HCV-RNA titers bound to LDL were evaluated. Fifteen untreated patients with $\mathrm{CHC}$ and hyperlipidemia were used as controls. ${ }^{25}$ Triglyceride (TG) shows differed significantly with the glutathione (GSH). When we compare the lipid profile parameters the total cholesterol level is very high in interferon subjected patients as compared to the interferon intolerance subjected patients of HCV. Different research approved that cholesterol increased the proliferation of the hepatitis $\mathrm{C}$ virus. Therefore those individuals which have high level of lipids have more chances of HCV infection. Likewise low density lipoprotein which is harmful to the body was found at high level in the interferon subjected positive patients as compared to the interferon intolerance $\mathrm{HCV}$ patients. In contrast to its high density lipoprotein which is beneficial to the body, showed low level in interferon positive patients as compared to the interferon intolerance patients?

The reports from several studies have produced clear evidence that there exists a good correlation between type and severity of disease and antioxidant level in the blood. ${ }^{34}$ Although the main role of the immunological mechanisms in pathogenesis of the chronic viral hepatitis $\mathrm{B}$ and $\mathrm{C}$ was demonstrated, researchers also concentrate on the problem of oxidative stress in the pathology of the diseases. Oxidative stress develops when the disturbances between reactive oxygen forms are produced in excess and the factors preventing their harmful effects occur. Enzymatic antioxidant defense of the organism includes: SOD, CAT, and GSH-Px. Superoxide dismutase protects a cell from toxic effect of superoxide radicals as it catalyzes the dis-mutation reaction of the radicals. ${ }^{35}$ Glutathione peroxidase decomposes hydrogen peroxide but it also converts lipid peroxides to harmless molecules protecting the cells from the consequences of lipid peroxidation. GSHPx removes $\mathrm{H}_{2} \mathrm{O}_{2}$ by the oxidation of reduced glutathione. Oxidized glutathione (GSSG) is produced and it is reduced again by glutathione reductase, and the NADPH (produced in pentose cycle). ${ }^{15}$ Oxidative stress has been detected in almost all clinical and experimental conditions of the chronic liver diseases. ${ }^{36,37}$ There are many studies about the oxidant stress in chronic hepatitis C patients. ${ }^{38}$ Showed that MDA, a product of polyunsaturated fatty acid peroxidation, was elevated in the liver and the blood. ${ }^{39}$ Also demonstrated MDA-protein adducts immunohistochemical in infected liver tissues, ${ }^{35,36}$ showed that the peripheral blood mononuclear cells from patient of chronic hepatitis $\mathrm{C}$ had increased MDA concentrations, and enhanced SOD activity. MDA is reflection of lipidperoxidation and SOD is an important antioxidant defense enzyme that converts superoxide into hydrogen peroxide. Increased SOD activity appears to be an adaptive response to increased generation of the superoxide ions ${ }^{40}$ showed higher serum malondialdehyde values in chronic hepatitis $\mathrm{C}$ patients than healthy subjects before the interferon treatment.

Current study showed that serum MDA has significant negative correlation to the glutathione in HCV patients receiving interferon. If the level of the MDA is increased then the level of the glutathione decreases and vice versa. The results presented confirm the involvement of the oxidative stress as a part of pathophysiology of HCV. Our findings support the existence of the oxidative stress in patients with chronic HCV infection. When we look the overall result of the stress biomarkers, malondialdehyde is produced as the byproduct of the lipid peroxidation. Therefore MDA level is increased in interferon positive patients as compared to the interferon intolerance patients. MDA is the cytotoxic metabolites which damage the DNA, protein and lipids leading to the cell death. Other stress biomarkers which are catalase, glutathione, and superoxide dismutase are antioxidants which are used to stop the lipid peroxidation, have low level in the interferon receiving HCV patients as compared to the interferon intolerance and control patients. This may be due to the disturbance of the oxidants and antioxidants in the infected cells.

Glutathione (GSH), the most abundant non-enzymatic antioxidant present in the cell, plays an important role in the defense against oxidative-stress-induced cell injury. In the cells glutathione is present mainly in its reduced form. Reduced GSH can be converted to oxidized glutathione (GSSG) with the GSH-Px, which is reversible to the reduced form with the glutathione reductase (GR). Cells are also equipped with the enzymatic antioxidant mechanisms that play an important role in the elimination of free radicals. ${ }^{35}$ Suarez studied the group of 100 individuals with chronic hepatitis C. They demonstrated GSH decrease in the blood serum of patients who were not treated with interferon. In contrast, GSH concentration was higher in the blood of patients responding satisfactorily to the treatment. The author set forth a theory explaining the cytopathic effect of a virus causing glutathione deficiency. Kramer studied antioxidant enzymes and they found diminished GSH-Px level in the blood serum and the erythrocytes, in patients with abnormal liver function. ${ }^{15,40} \mathrm{Pak}$ also demonstrated low activities of GSH-Px and SOD in adults with acute hepatitis B. Results of our study are consistent with the reports by Suarez and associates. In the current study we demonstrated that glutathione peroxidase level and superoxide dismutase level are decreased in erythrocytes of patients with chronic hepatitis C. It probably decreased the antioxidant barrier efficiency in studied CHC patients. When the activity of the enzymes mentioned above is insufficient, an organism is not capable to neutralize free oxygen radicals that are produced in excess. In consequence, it leads to hepatocyte lesion. ${ }^{15}$ They demonstrated that SOD and catalase levels decreased both in group of children with chronic hepatitis C, and B. Kramer and associates et al, studied the small group of children with abnormal function of liver cell, and demonstrated decreased activity of SOD in comparison to the healthy children. Loginow et al. studied antioxidant system in adults with chronic active hepatitis, and demonstrated SOD decrease correlating with severity of inflammatory process. Study by Yasuyama showed decrease of SOD levels in liver tissue of patients with acute ${ }^{41}$ and chronic hepatitis accompanied by fatty degeneration while comparing with patients with the liver inflammatory diseases of different etiology. In another study Irshad et al., ${ }^{42}$ found SOD activity significantly low in the chronic active hepatitis $\mathrm{C}$ patients.

\section{Conclusion}

My great finding in these results is that zinc ( $\mathrm{Zn}$ ) shows the lower level in interferon intolerance patients as compared to the interferon positive patients and control groups. And this might be reason to the intolerance of the interferon. According to my finding if a person who is intolerant to the interferon should be subjected to zinc along with the interferon therapy.

\section{Acknowledgements}

I am highly thankful to Sakhawat Ali, Intizar Ali, Sharafat Ali, Wajid Ali, Abdul Rehman, Riast Ali, Bahadur Ali, and Ali Hamza for helping me regarding this. 


\section{Conflict of interest}

The authors declare that there is no conflict of interest.

\section{References}

1. Ryan KJ, Ray CG. Sherris Medical Microbiology 4th ed, McGraw Hill; 2004:551-552

2. Ozaras R, Tahan V. Acute hepatitis C: prevention and treatment. Expert Rev Anti Infect Ther. 2009;7(3):351-361.

3. Rosen HR. Clinical practice. Chronic hepatitis C infection. $N$ Engl J Med. 2011;364 (25):2429-2438.

4. Wilkins T, Malcolm JK, Raina D, et al. Hepatitis C: diagnosis and treatment. Am Fam Physician. 2010;81(11):1351-1357.

5. Lotersztajn S, Julien B, Teixeira-Clerc F, et al. Hepatic Fibrosis: Molecular Mechanisms and Drug Targets. Annu Rev Pharmacol Toxicol. 2005;45:605-628.

6. Kamel IR, Bluemke DA. J Vasc Intervent Radiol. 2002;13:173-184

7. Chance B, Sies H, Boveris A. Hydroperoxide metabolism in mammalian organs. Physiol Rev. 1979;59(3):527-605.

8. Cerutti PA. Oxy-radicals and cancer. Lancet. 1994;344(8926):862-863.

9. Wiseman H, Halliwell B. Damage to DNA by reactive oxygen and nitrogen species: role in inflammatory disease and progression to cancer Biochem J. 1996;313(pt 1):17-29.

10. Adler $\mathrm{V}$, Yin $\mathrm{Z}$, Tew $\mathrm{KD}$, et al. Role of redox potential and reactive oxygen species in stress signaling. Oncogene. 1999;18(45): 6104-6111.

11. Larrea E, Beloqui O, Muñoz-Navas MA, et al. Superoxide dismutase in patients with chronic hepatitis $\mathrm{C}$ virus infection. Free Radic Biol Med 1998;24(7-8):1235-1241.

12. Sies H. Strategies of antioxidant defense. Eur $J$ Biochem. 1993;215(2):213-219.

13. Dalle-Donne I, Scaloni A, Giustarini D, et al. Proteins as biomarkers of oxidative stress in diseases: the contribution of redox proteomics. Mass Spectrom Rev. 2005;24(1):55-99.

14. Davies MJ, Fu S, Wang H, et al. Stable markers of oxidant damage to proteins and their application in study of human disease. Free Radic Biol Med. 1999;27(11-12):1151-1161.

15. Chrobot AM, Szaflarska-Szczepanik A, Drewa G. Antioxidant defense in children with chronic viral hepatitis B and C. Med Sci Monit. 2000;6(4):713-718.

16. Diczfalusy U, Falardeau P, Hammarström S. Conversion of prostaglandin endoperoxides to C17-hydroxy acids catalyzed by human platelet thromboxane synthase. FEBS Lett. 1977;84(2):271-274.

17. Abou Ghalia AH, Fouad IM. Clin Biochem. 2000;33:657-662.

18. Oberley TD, Oberley LW. Histol Histhopathol. 1997;12:525-535.

19. Hayes JD, McLellan LI. Glutathione and glutathione-dependent enzymes represent a co-ordinately regulated defence against oxidative stress. Free Radic Res. 1991;31(4):273-300.

20. Goldberg DM, Spooner RJ. Glutathione reductase. In: Bergmeyen HV (Eds.), Methods of enzymatic analysis, 3rd edn. USA: Academic Press; 1983.

21. Sundberg AG, Nilsson R, Appelkvist EL, et al. Immunohistochemica localization of alpha and Pi class glutathione transferases in normal human tissues. Pharmacol Toxicol. 1993;72(4-5): 321-331.

22. Knapen MF, Peters WH, Mulder TP, Steegers EA (2000) A marker for hepatocellular damage. Lancet. 355(9213):1463-1464.
23. KA Mahdy A. Abd-El-Shaheed ME, Khadr, El-Shamy (2009) Antioxidant status and lipid peroxidation activity in evaluating hepatocellular damage in children. Eastern Mediterranean Health Journal. 15(4):842-852.

24. Dikici I, Mehmetoglu I, Dikici N, et al. Investigation of oxidative stress and some antioxidants in patients with acute and chronic viral hepatitis B and the effect of interferon- $\alpha$ treatment. Clin Biochem. 2005;38(12):1141-1144.

25. Davis GL, Balart LA, Schiff ER, et al. Treatment of chronic hepatitis C with recombinant interferon Alfa. A multicenter, randomized, controlled trial. N Engl J Med. 1989;321(22):1501-1506.

26. Fujita N, Kaito M, Kai M, et al. Effects of bezafibrate in patients with chronic hepatitis $\mathrm{C}$ virus infection: combination with interferon and ribavirin. J Viral Hepat. 2006;13(7):441-448.

27. Marnett LJ. Lipid peroxidation-DNA damage by malondialdehyde Mutat Res. 424(1-2):83-95.

28. McHutchison JG, Gordon SC, Schiff ER, et al. Interferon alfa-2b alone or in combination with ribavirin as initial treatment for chronic hepatitis C. N Engl J Med. 1998;339(21):1485-1492.

29. Fried MW, Shiffman ML, Reddy KR, et al. Peginterferon alfa-2a plus ribavirin for chronic hepatitis $\mathrm{C}$ virus infection. $N$ Engl $\mathrm{J}$ Med. 2002;347(13):975-982.

30. Hauser P. Neuropsychiatric side effects of HCV therapy and their treatment: focus on IFN alpha-induced depression. Gastroenterol Clin North Am. 2004;33(1suppl):S35-S50.

31. Torriani FJ, Rodriguez-Torres M, Rockstroh JK, et al. Peginterferon alfa2a plus ribavirin for chronic hepatitis $\mathrm{C}$ virus infection in $\mathrm{HIV}$-infected patients. N Engl J Med. 2004;351(5):438-450.

32. Nutley NJ. Hoffman-La Roche Inc Pegasys. 2002

33. Halliwell B, Whiteman M. Measuring reactive species and oxidative damage in vivo and in cell culture: how should you do it and what the results mean? Br J Pharmacol. 2004;142(2):231-255.

34. Jilani T, Iqbal MP. Does vitamin $E$ have a role in treatment and prevention of anemia? Pak J Pharm Sci. 2011;24(2):237-242.

35. Irshad M, Chaudhuri, Joshi YK. Superoxide dismutase and tota anti-oxidant levels in various forms of liver diseases. Hepatol Res. 2002;23(3):178-184

36. Boya $\mathrm{P}$, de la Peña A, Beloqui $\mathrm{O}$, et al. Antioxidant status and glutathione metabolism in peripheral blood mononuclear cells from patients with chronic hepatitis C. J Hepatol. 1999;31(5):808-814.

37. Parola M, Robino G. Oxidative stress-related molecules and liver fibrosis. J Hepatol. 2001;35(2):297-306.

38. De Maria N, Colantoni A, Fagiuoli S, et al. Association between reactive oxygen species and disease activity in chronic hepatitis C. Free Radic Biol Med. 1996;21(3):291-295.

39. Paradis V, Mathurin P, Kollinger M, et al. In situ detection of lipid peroxidation in chronic hepatitis $\mathrm{C}$ : correlation with pathological features. J Clin Pathol. 1997;50(5):401-406.

40. Romero MJ, Bosch-Morell F, Romero B, et al. Serum Malondialdehyde: Possible use for the clinical management of chronic hepatitis $\mathrm{C}$ patients. Free Radic Biol Med. 1998;25(9):993-997.

41. Pak SG, Nikitin EV. Status of the processes of free radicaloxidation and antioxidation system in patients with a severe course of hepatitis B. Klin Med (Mosk). 1991;69(9):54-57.

42. Loginov AS, Matiushin BN, Tkachev VD. Enzyme system for dismutation of active forms of oxygen in the liver during chronic impairment of hepatobiliary system. Vopr Med Khim. 1991;37(1):31-33. 